\title{
Synthesis of micro-mesoporous molecular sieve ZSM-5/SBA-15: tuning aluminium content for tert-butylation of phenol
}

\author{
LING XU', QIANG ZHANGa ${ }^{\mathrm{a}}$, MIAO ZHANG ${ }^{\mathrm{a}}$, LILI MAO ${ }^{\mathrm{a}}$, JING HU ${ }^{\mathrm{a}}$, ZONGRUI LIU, ${ }^{\mathrm{a} *}$ and \\ YAN XIE ${ }^{\mathrm{b}, *}$ \\ ${ }^{a}$ College of Chemistry and Chemical Engineering, Inner Mongolia University for Nationalities, Tongliao Inner \\ Mongolia 028000, China \\ ${ }^{\mathrm{b}}$ Gold Catalysis Research Center, State Key Laboratory of Catalysis, Dalian Institute of Chemical Physics, \\ Chinese Academy of Sciences, 457 Zhongshan Road, Dalian 116023, China \\ E-mail: yanxie@dicp.ac.cn; tlxuling1979@163.com; liuzr716@163.com
}

MS received 16 December 2018; revised 12 March 2019; accepted 13 March 2019; published online 9 May 2019

\begin{abstract}
Micro-mesoporous ZSM-5/SBA-15 molecular sieve was derived from mesoporous molecular sieves SBA- 15 by hydrothermal crystallization approach. The silica-alumina ratio significantly affects the structure and catalytic performance of ZSM-5/SBA-15. When the $\mathrm{n}_{\mathrm{Si}} / \mathrm{n}_{\mathrm{Al}}$ is less than 25 , the two-dimensional hexagonal pore structure of SBA-15 keeps intact with relatively low crystallinity of the pore wall. However, when the $n_{\mathrm{Si}} / \mathrm{n}_{\mathrm{Al}}$ is larger than 50 , the SBA- 15 pores are severely damaged. When $n_{S_{i}} / n_{A 1}$ is 25 , the catalyst ZSM-5/SBA- 15 retains relatively good pore structure and shows excellent catalytic performance with $96.2 \%$ phenol conversion and $53.5 \%$ selectivity to 2,4-ditert-butyl phenol in the tert-butylation of phenol.
\end{abstract}

Keywords. SBA-15; ZSM-5; micro-mesoporous molecular sieve; phenol tert-butylylation.

\section{Introduction}

Alkylation of phenol is considered to be an important reaction, as alkylated phenols are extensively used as crucial intermediates to manufacture antioxidants, polymerization inhibitors, ultraviolet absorbers, lube additives, phenolic resins, and heat stabilizers for polymeric materials. ${ }^{1}$ Great efforts have been made for tert-butylation of phenols over various catalysts, including zeolites, ${ }^{2-4}$ hydrotalcites, ${ }^{5}$ clays, ${ }^{6,7}$ heteropolyacids, ${ }^{8,9}$ modified mesoporous aluminophosphates, ${ }^{10}$ modified mesoporous zirconias ${ }^{11,12}$ and mixed oxides. ${ }^{13}$ Generally, the use of homogeneous acid catalysts is not desired due to their non-renewability, corrosivity, and poor heat resistibility properties. Therefore, many investigations have focused on the potential applications of microporous zeolites and mesoporous materials due to their high thermal stability and recyclability.

Since Mobile Corporation developed the M41s series of mesoporous molecular sieves in 1992, great efforts have been widely made on an unprecedented fiery situation in the field of mesoporous materials. ${ }^{14-18}$ The application of mesoporous molecular sieves in acid catalysis is seriously restricted due to the relatively low acidity and relatively poor hydrothermal stability. Hierarchically porous molecular sieves with partially crystallized mesoporous walls can take good advantages and further effectively combine micro-mesoporous structure to enhance catalytic reaction. Compared to the pure microporous molecular sieves, micro-mesoporous porous molecular sieves with a larger mesoporous pore size greatly accelerate the mass transferability. The partial crystallization of mesoporous molecular sieves with suitable acidity and good hydrothermal stability can boost their acid catalytic performance. ${ }^{19-27}$

Relatively few reports focused on the preparation of micro-mesoporous molecular sieves by mesoporous wall crystallization, mainly due to the small pore wall thickness that is difficult to be completely crystallized. Huang et al., ${ }^{28}$ synthesized the ZSM-5/MCM41 composite molecular sieve by partially crystallizing the amorphous pore wall of MCM-41 through a

\footnotetext{
*For correspondence

Electronic supplementary material: The online version of this article (https://doi.org/10.1007/s12039-019-1619-4) contains supplementary material, which is available to authorized users.
} 
two-step crystallization process, in which the crystallization time was controlled at the second step. The catalytic cracking of dodecane over ZSM-5/MCM41 composite molecular sieve $(9.0 \%)$ was higher than that of mechanically mixed ZSM-5 and MCM-41, indicating that interconnection of micropores and mesopores were more favorable for the reaction. The molecules contacted the active center and improved the catalytic cracking performance. While the preparation process with two-step crystallization was relatively complicated. Kloetstra et al., ${ }^{29}$ introduced tetrapropyl ammonium ion $\left(\mathrm{TPA}^{+}\right)$into the pore walls of synthetic mesoporous MCM-41 and HMS molecular sieves, followed by recrystallization to obtain microporous and mesoporous composite molecular sieves, namely PAN1 and PAN-2. The catalytic conversion over two kinds of composite molecular sieves was increased by about $24.0 \%$, relative to that of the corresponding MCM-41 and HMS. However, this method had strict requirements on the synthesis conditions. Verhoef et al., ${ }^{30}$ introduced $\mathrm{TPA}^{+}$into MCM-41 mesoporous molecular sieves via a hydrothermal treatment to partially crystallize the pore walls into a ZSM-5 structure. It was found that the mesoporous wall can be only crystallized under certain alkaline conditions ( $\mathrm{pH}>9$ ), while the mesoporous structure severely collapsed under such high alkaline conditions.

Extensive studies have enabled the conversion of mesoporous structures with amorphous walls to crystalline zeolite frameworks. Dry gel conversion in the presence of an organic microporous SDA results in ordered mesoporous substances, such as SBA-15 and MCM-41, undergoing partial crystallization on their walls to give a zeolitic structure. ${ }^{31,32}$ This method leads to the intercrystalline mesopore formation. Clearly, the factors (including the morphology, topology and phase purity of the zeolite crystals) and parameters (typically refers to the distribution, location, size, shape, and interconnectivity of the mesopores) are closely related to the template type and good interaction with aluminosilicate species in the synthesis gels. Unfortunately, the zeolite and mesoporous substrates nucleate synchronously result in the formation of a physical mixture with these two components during conventional hydrothermal synthesis. Moreover, crystallization of mesopore walls to zeolites with different crystalline and amorphous phase densities leads to the breakage of the aluminosilicate framework, so that the partial collapse of the final mesostructured material occurs. ${ }^{33}$ Herein, microporous template tetrapropyl ammonium hydroxide (TPAOH) and aluminum sulfate aqueous solution $\left(\mathrm{Al}_{2}\left(\mathrm{SO}_{4}\right)_{3}\right)$ were used to prepare ZSM-5/SBA-15 composite through a hydrothermal method. Meanwhile, the effect on the addition of $\mathrm{Al}_{2}\left(\mathrm{SO}_{4}\right)_{3} \cdot 18 \mathrm{H}_{2} \mathrm{O}$ in the mesoporous pore wall crystallinity was investigated. The obtained ZSM-5/SBA-15 materials with different addition of aluminum were evaluated in the phenol tertbutylation reaction to discuss the relationship between the synthesis parameters and acid catalysis performance.

\section{Experimental}

\subsection{Chemicals}

All materials were used directly as received. Polyethylene oxide-polypropylene oxide-polyethylene oxide (P123) was purchased from Sigma company (America). $\mathrm{NaOH}$ were purchased from Da Mao Chemical Reagent Factory (Analytical purity, Tianjin, China), $\mathrm{HCl}$ was purchased form $\mathrm{Da}$ Mao Chemical Reagent Factory (Analytical purity, Tianjin, China), aluminum sulfate 18-hydrated and ammonium nitrate were purchased form Da Mao Chemical Reagent Factory (Analytical purity, Tianjin, China). Tetraethyl orthosilicate (TEOS) and tetrapropylammonium hydroxide (TPAOH) were obtained from the chemical reagent of national medicine group (Analytical purity, Shenyang, China).

\subsection{Catalyst preparation}

2.2a Preparation of SBA-15 molecular sieve: $4.0 \mathrm{~g}$ of polyethylene oxide-polypropylene oxide-polyethylene oxide (P123) solid was added into a beaker containing $105 \mathrm{~mL}$ of distilled water and $20 \mathrm{~mL}$ of concentrated hydrochloric acid mixed solution, which was stirred at a constant temperature of $40{ }^{\circ} \mathrm{C}$ for $3 \mathrm{~h}$. Then $9.2 \mathrm{~mL}$ of tetraethyl orthosilicate was slowly added with a continued stirring for $4 \mathrm{~h}$. The suspension was placed in a Teflon-lined reactor at $100^{\circ} \mathrm{C}$ for $24 \mathrm{~h}$. After suction filtration and subsequent washing and drying, it was calcined in a muffle furnace at $550^{\circ} \mathrm{C}$ for $5 \mathrm{~h}$ to remove the template P123. Finally, a mesoporous molecular sieve SBA15 was obtained.

\section{$2.2 \mathrm{~b}$ Preparation of pore wall crystallization SBA-15} molecular sieve: Different dosages of aluminum sulfate 18-hydrated solids $(0.55 \mathrm{~g}, 0.33 \mathrm{~g}, 0.17 \mathrm{~g})$ were mixed with $1.5 \mathrm{~g}$ mesoporous SBA-15 molecular sieve, $0.13 \mathrm{~g} \mathrm{NaOH}$, $36 \mathrm{~mL} \mathrm{H}_{2} \mathrm{O}$, and $1.5 \mathrm{~mL}$ tetrapropylammonium hydroxide (TPAOH) and stirred for $12 \mathrm{~h}$ in the reactor at $160^{\circ} \mathrm{C}$ for 72 h. After thoroughly washing, drying, and calcining at $550^{\circ} \mathrm{C}$ for $5 \mathrm{~h}$ in air, a white powder material was obtained. The sample was denoted according to the silica-alumina ratio, namely $\mathrm{n}$-SBA-15 $(\mathrm{n}=15,25$ and 50).

\section{2c Preparation of H-type pore wall crystallization} SBA-15 molecular sieve: $1.5 \mathrm{~g}$ of ion-exchanged molecular sieve, $24.0 \mathrm{~g}$ of ammonium nitrate and $100 \mathrm{~mL}$ of distilled water were mixed and stirred for $5 \mathrm{~h}$ in a water bath at $90{ }^{\circ} \mathrm{C}$ to complete the first ion exchange. After filtration and drying, the second ion exchange was carried out. The ZSM-5/SBA-15 
molecular sieves were dried and ion-exchanged twice, placed in a muffle furnace and calcined at $500{ }^{\circ} \mathrm{C}$ for $5 \mathrm{~h}$ to obtain H-type ZSM-5/SBA-15 molecular sieves.

\subsection{Catalysts characterization}

X-ray diffraction was performed on a Bruker D8 (Bruker Company, Germany) with Ni-filtered $\mathrm{Cu}$ target $\mathrm{K} \alpha$-ray (operation at $30 \mathrm{kV}, 40 \mathrm{~mA}$, wavelength $\mathrm{k}=0.15418 \mathrm{~nm})$. Nicolet-5700 Fourier Infrared Spectrometer (Nikoli, USA) and Hitachi S4800 Transmission Electron Microscope (Japan Hitachi) and JEM-2100F electron microscope (Japan, JEOL) at an accelerating voltage of $200 \mathrm{kV}$ were used to analyze the samples.

$\mathrm{N}_{2}$ adsorption/desorption isotherms were recorded at 77 $\mathrm{K}$ with an ASAP 2020 (Micromeritics, USA). Before measurements, samples were out-gassed at $573 \mathrm{~K}$ for $3 \mathrm{~h}$. The specific surface area and pore volume of the sample were measured. The sample was degassed at $573 \mathrm{~K}$ for $3 \mathrm{~h}$ and absorbed at liquid nitrogen temperature before determination. BET specific surface area is calculated by the BET equation, and BJH square is used. The mesoporous distribution (PSD) of the samples was calculated from the adsorption branch of the isothermal curve, and the total pore volume was obtained at the relative pressure of about 0.974 .

${ }^{27}$ Al-MAS NMR spectra were determined on a $600 \mathrm{M}$ spectrometer (Agilent, USA), operating at a magnetic field of $\mathrm{B}_{0}=0.94 \mathrm{~T}$ with $\mathrm{NMR}$ frequencies of $104 \mathrm{MHz}$, at a spin rate of $10 \mathrm{kHz}$. The chemical shifts were referenced to $\mathrm{Al}\left(\mathrm{H}_{2} \mathrm{O}\right)_{6}{ }^{3+}$. $\mathrm{NH}_{3}$-TPD spectra was measured using a fixed-bed reactor connected to a thermal conductivity detector (TCD). Sample $(0.05 \mathrm{~g})$ was activated at $773 \mathrm{~K}$ for $1 \mathrm{~h}$ in pure nitrogen flow, then cooled down to $373 \mathrm{~K}$, and begin to adsorb ammonia for $0.5 \mathrm{~h}$. Physically adsorbed ammonia was removed by pure nitrogen flow at $373 \mathrm{~K}$. Ammonia desorption measurements were achieved in the range of 373-773 K to increase the temperature at $10 \mathrm{~K} \mathrm{~min}^{-1}$.

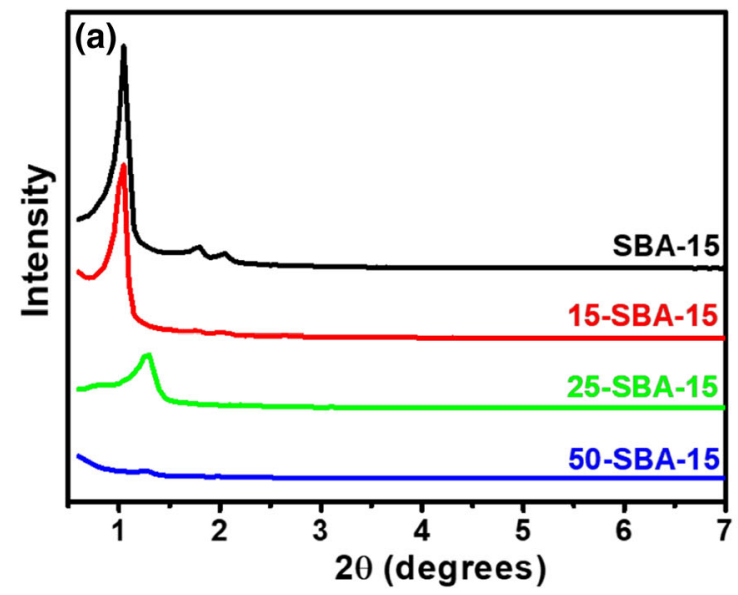

\subsection{Catalytic test}

The product was analyzed by a fixed-bed reactor as a micro-quantitative reactor and a gas chromatograph. $0.5 \mathrm{~g} \mathrm{H}-$ type ZSM-5/SBA-15 molecular sieve was used as a catalyst for the reaction. The molar ratio of reactant phenol to tertbutanol was 1:2.5. The injection volume was $2.2 \mathrm{~mL} \mathrm{~h}^{-1}$ and the reaction temperature was $418 \mathrm{~K}$. The reaction product was dissolved in absolute ethanol and the product was analyzed by a gas chromatograph. The area normalization method was used to obtain the conversion of phenol and the selectivity of each reaction product.

\section{Results and Discussion}

\subsection{Analysis of XRD Results}

Small-angle and wide-angle X-ray diffraction (XRD) spectra were conducted on mesoporous molecular sieves SBA-15 and n-SBA-15 (15, 25 and 50) in Figure 1. SBA-15 shows diffraction peaks at the (100), (110) and (200) planes of SBA-15 at $2 \theta$ of $0.8^{\circ}, 1.6^{\circ}$ and $1.8^{\circ}$, indicating that SBA-15 has a long-range order of two-dimensional hexagonal mesoporous structure (Figure 1a). With the addition of $\mathrm{Al}_{2}\left(\mathrm{SO}_{4}\right)_{3} \cdot 18 \mathrm{H}_{2} \mathrm{O}$ and TPAOH alkaline solution into the SBA-15 molecular sieve, the diffraction peak intensity of SBA-15 clearly decreases, suggesting that the long-range ordered mesoporous structure of SBA-15 has been destroyed. With the higher amount of aluminum, the XRD spectra of 15-SBA-15 demonstrates that the (100), (110) and (200) crystal faces of SBA-15 are still observable. The weaker peak intensity indicates that the long-range order is slightly reduced but the 2-D hexagonal mesoporous structure still maintains. Further increasing the aluminum amount in the catalyst of 50-SBA-15, no

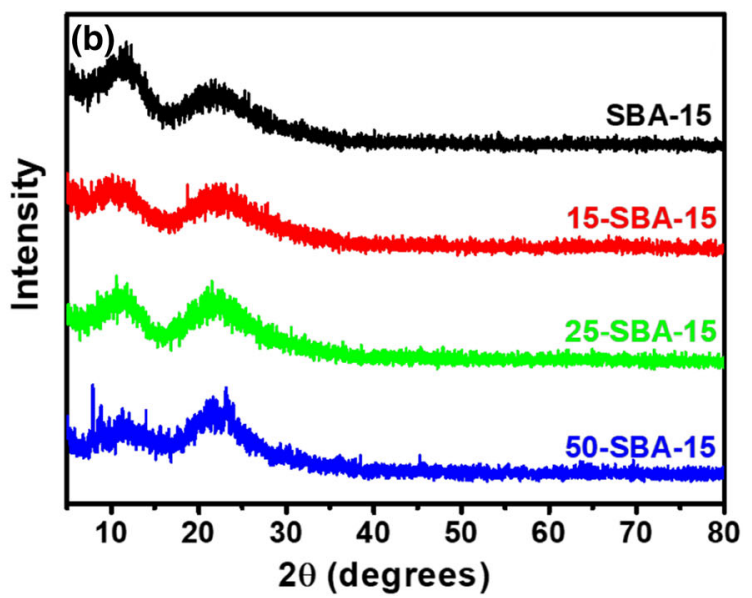

Figure 1. (a) Small-angle and (b) wide-angle XRD spectra of the samples: SBA-15 (black line) and $\mathrm{n}-\mathrm{SBA}-15$ ( $\mathrm{n}=15$, red line; 25 , green line and 50, blue line). 


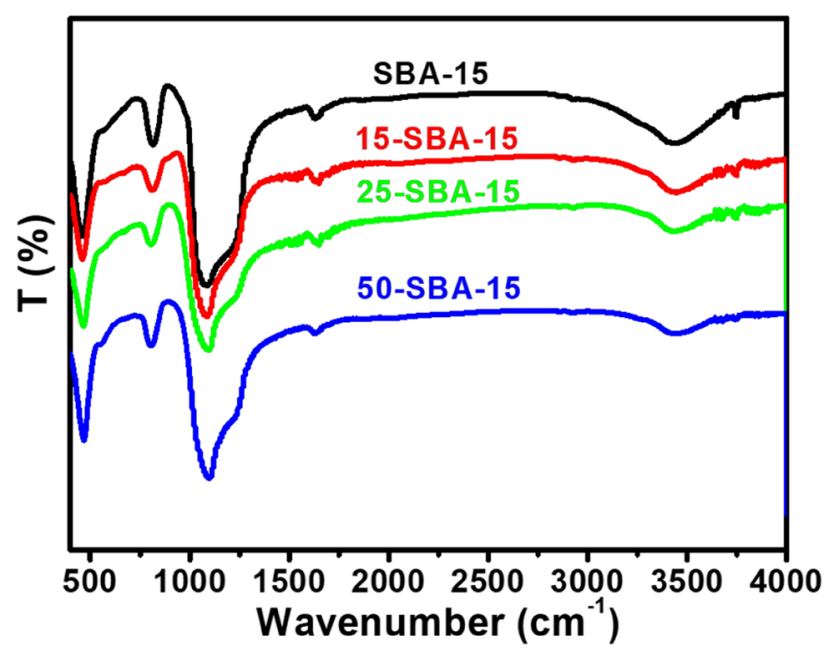

Figure 2. FT-IR spectra of the samples: SBA-15, black line; 15-SBA-15, red line; 25-SBA-15, green line and 50-SBA-15, blue line.

obvious diffraction peaks are detected, suggesting that the two-dimensional hexagonal mesoporous structure of SAB-15 seriously damaged in Figure 1a. It is noted that the wide-angle XRD of SBA-15 and n-SBA- 15 ( $\mathrm{n}=15$, 25 and 50) in Figure 1b exhibits that the pore wall of SBA-15 is amorphous or the size of pore walls is too thin. A characteristic diffraction peak can be attributed to the zeolite ZSM-5 appeared in the XRD spectrum. As a result, the increasing content of the aluminum slows down the crystallization rate of the zeolite. Therefore, the ZSM-5 zeolite crystal is preferentially formed in the system with low aluminum content and the SBA-15 mesopores channel is destroyed. In combination with the small-angle XRD pattern analysis of the sample in Figure 1a, the higher the aluminum content is, the lower the crystallinity of the pore wall is. Lowering the aluminum content, the mesoporous order of the sample is reduced, and the crystallinity of the pore wall is higher. It is easier to form ZSM-5 crystal with less addition of aluminum sulfate octahydrate. According to the literature, the higher ratio of silicon to aluminum is beneficial to form the MFI topology. ${ }^{20}$

\subsection{Characterization of FT-IR results}

Figure 2 shows the FT-IR spectra of the samples. The infrared spectrum of SBA-15 displays typical peaks located at $3430 \mathrm{~cm}^{-1}$ and the $1630 \mathrm{~cm}^{-1}$, which can be ascribed as the stretching vibration absorption peak of $\mathrm{Si}-\mathrm{OH}$, and the bending vibration absorption peak of $\mathrm{Si}-\mathrm{OH}$, respectively. The peaks centered at $1080 \mathrm{~cm}^{-1}$ can be ascribed as the vibration absorption peak produced by the anti-symmetrical stretching of Si-O-Si. The wide shoulder peak of $\mathrm{Si}-\mathrm{O}$ ranging from 900 to $1450 \mathrm{~cm}^{-1}$ in the catalyst of $25-\mathrm{SBA}-15$ could be deconvoluted consistently into three distinctly separate peaks at around $1024 \mathrm{~cm}^{-1}, 1090 \mathrm{~cm}^{-1}$ and $1200 \mathrm{~cm}^{-1}$ in Figure S1, Supplementary Information. These observations could be supportive of at least two structural models of silicon dioxide disclaiming the generally accepted continuous random network arrangement. The symmetrical stretching vibration and bending vibration of Si-O-Si at $800 \mathrm{~cm}^{-1}$ and $460 \mathrm{~cm}^{-1}$ are generated. The absorption peak of the infrared spectrum of the sample after crystallization of $\mathrm{Al}_{2}\left(\mathrm{SO}_{4}\right)_{3} \cdot 18 \mathrm{H}_{2} \mathrm{O}$ and TPAOH are not significantly different from that of SBA- 15 . The samples of 25-SBA-15 and 50-SBA-15 exhibits weaker infrared absorption at $550 \mathrm{~cm}^{-1}$, indicating secondary structural units of ZSM-5 in the sample.

\subsection{Analysis of $\mathrm{N}_{2}$ adsorption-desorption results}

Figure 3 shows the $\mathrm{N}_{2}$ adsorption-desorption isotherms and the Barrett-Joyner-Halenda $(\mathrm{BJH})$ pore size distribution of n-SBA-15 ( $\mathrm{n}=15,25$ and 50) and SBA-15. As shown in Figure $3 a$, there is a typical IV with a hysteresis loop for $\mathrm{n}$-SBA-15 $(\mathrm{n}=15,25$ and 50 ), indicating the appearance of a mesoporous structure in the SBA-15 molecular sieve crystallized by the pore walls. The isothermal curve of 15-SBA-15 with larger initial addition of $\mathrm{Al}_{2}\left(\mathrm{SO}_{4}\right)_{3} \cdot 18 \mathrm{H}_{2} \mathrm{O}$ is similar to that of SBA-15, indicating that the higher content of aluminum results in lower crystallized mesoporous SBA-15. The $\mathrm{N}_{2}$ adsorption-desorption isotherm curve of 50-SBA-15 with a small initial addition amount of $\mathrm{Al}_{2}\left(\mathrm{SO}_{4}\right)_{3} \cdot 18 \mathrm{H}_{2} \mathrm{O}$ is quite different from that of SBA15. The smaller hysteresis loop of 50-SBA-15 further demonstrates that the ZSM-5 crystallized (structural unit) on the pore wall occupies the pore interior space. On the other hand, the isothermal curve of 50-SBA15 gradually changes from type IV to I, suggesting that the mesoporous of SBA-15 is destroyed when the mesoporous wall is crystallized into the ZSM-5 crystal. Figure $3 b$ shows the BJH pore size distribution of the samples. With the increasing ratio of $\mathrm{Si} / \mathrm{Al}$, the pore size of mesopores gradually decreases. This result may be related to the enhanced amount of ZSM-5 structural units and the increased crystallinity on the walls of SBA-15 pores, consequently leading to congested pores.

\subsection{Transmission electron microscope (TEM) results}

Transmission electron microscopy (TEM) technique has been employed to describe the morphologies of samples in Figure 4. The TEM image of 15-SBA-15 in Figure 4a shows relatively low (basically no crystals) 

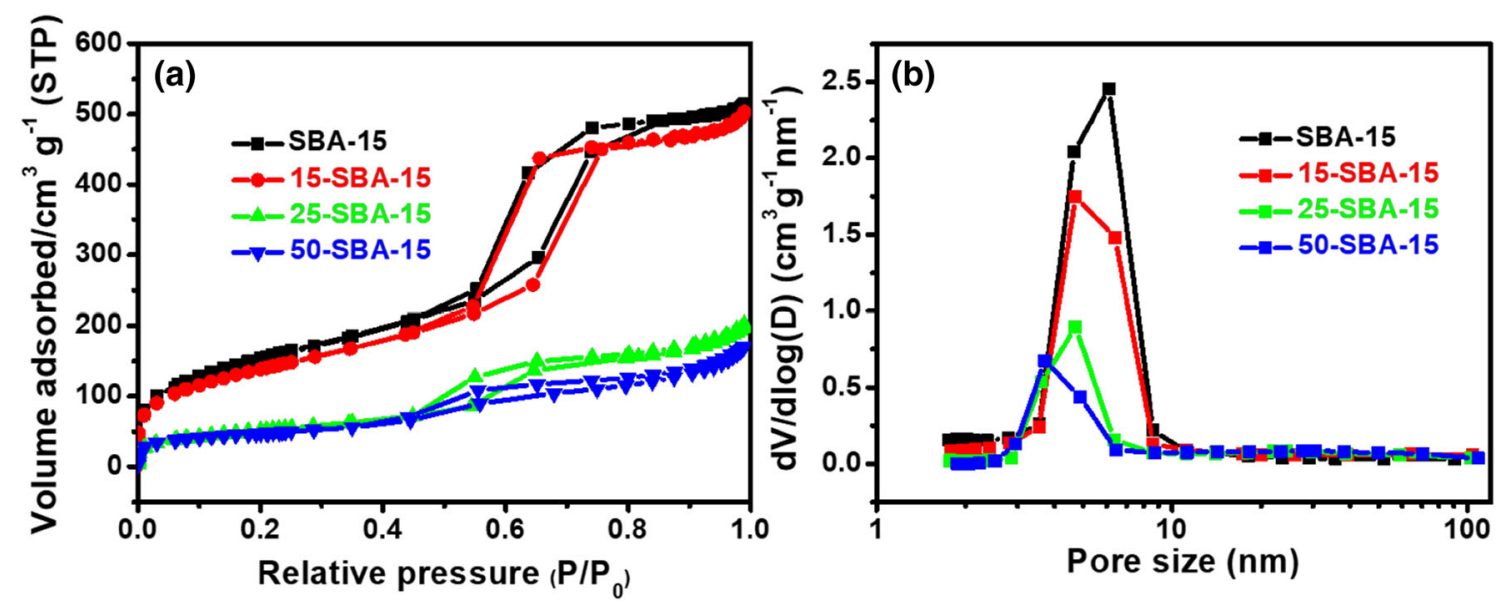

Figure 3. (a) $\mathrm{N}_{2}$ adsorption and desorption isotherms and (b) BJH pore size distribution of samples: SBA-15 (black line) and n-SBA-15 ( $\mathrm{n}=15$, red line; 25, green line; and 50, blue line).
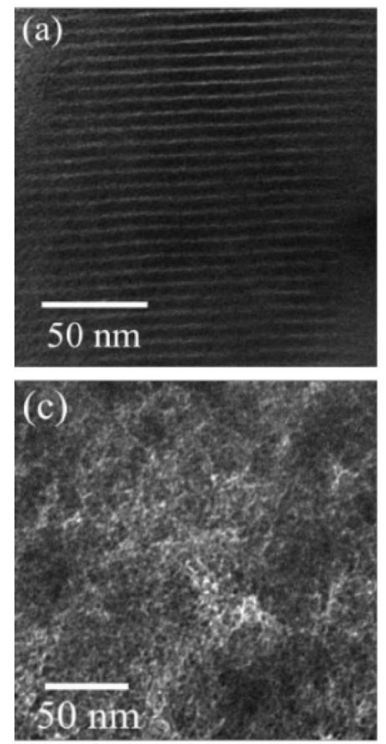
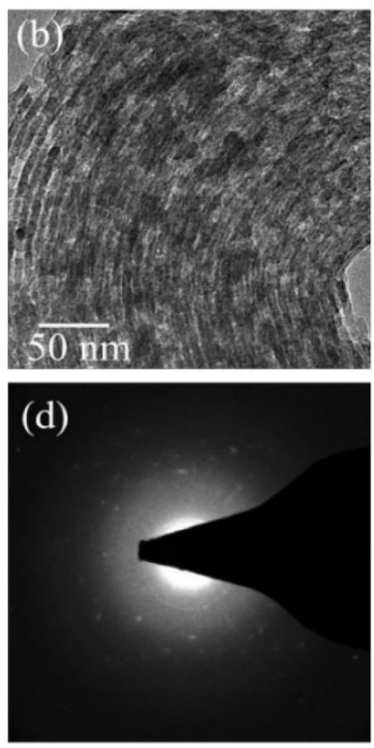

(e)
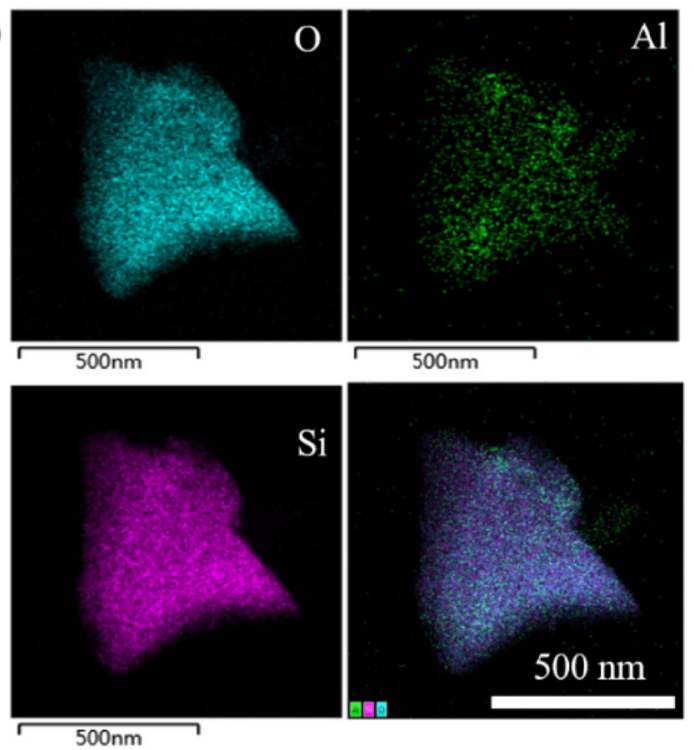

Figure 4. TEM images of samples: (a) 15-SBA-15; (b) 25-SBA-15; (c) 50-SBA-15; (d) SAED pattern of 25-SBA-15 and (e) element mapping and EDS layered image of 25-SBA-15.

crystallized pore wall due to the sample with higher aluminum. The SBA-15 still possesses the long-range and orderly two-dimensional hexagonal mesoporous structure that is similar to parent SBA-15. The TEM image of 25-SBA-15 in Figure $4 \mathrm{~b}$ demonstrates the appearance of channel characteristics in the parent SBA15. The distribution of the pores is relatively uniform, but the order of pores is reduced, owing to the SBA15 crystallized to ZSM-5 zeolite (structural unit). The electron diffraction results of 25-SBA-15 are shown in Figure $4 \mathrm{~d}$. The weak electron diffraction of 25-SBA-15 indicates that the pore walls of the sample crystallize into a smaller size crystal. This phenomenon is consistent with the previous characterization test. Based on the TEM image of $50-S B A-15$ in Figure $4 c$, it can be seen that the long-range ordered structure of SBA-15 almost disappears, resulting in some disordered pore structure. The TEM analysis shows that the two-dimensional hexagonal mesoporous structures of 15-SBA-15 and 25-SBA-15 maintain well with tiny ZSM-5 crystals. The mesoporous structure of 50-SBA15 essentially destroyed. This result is consistent with data from XRD, FT-IR, and $\mathrm{N}_{2}$ adsorption-desorption results. Furthermore, the element mapping and energy dispersive spectrometer (EDS) layered image of 25SBA-15 catalyst in Figure 4e, Figure S2 and Table S1 (Supplementary Information) show the uniform distribution of $\mathrm{O}, \mathrm{Al}$ and $\mathrm{Si}$ and the measured content of elemental composition and content. The element content was detected in Table S1 (Supplementary Information) 

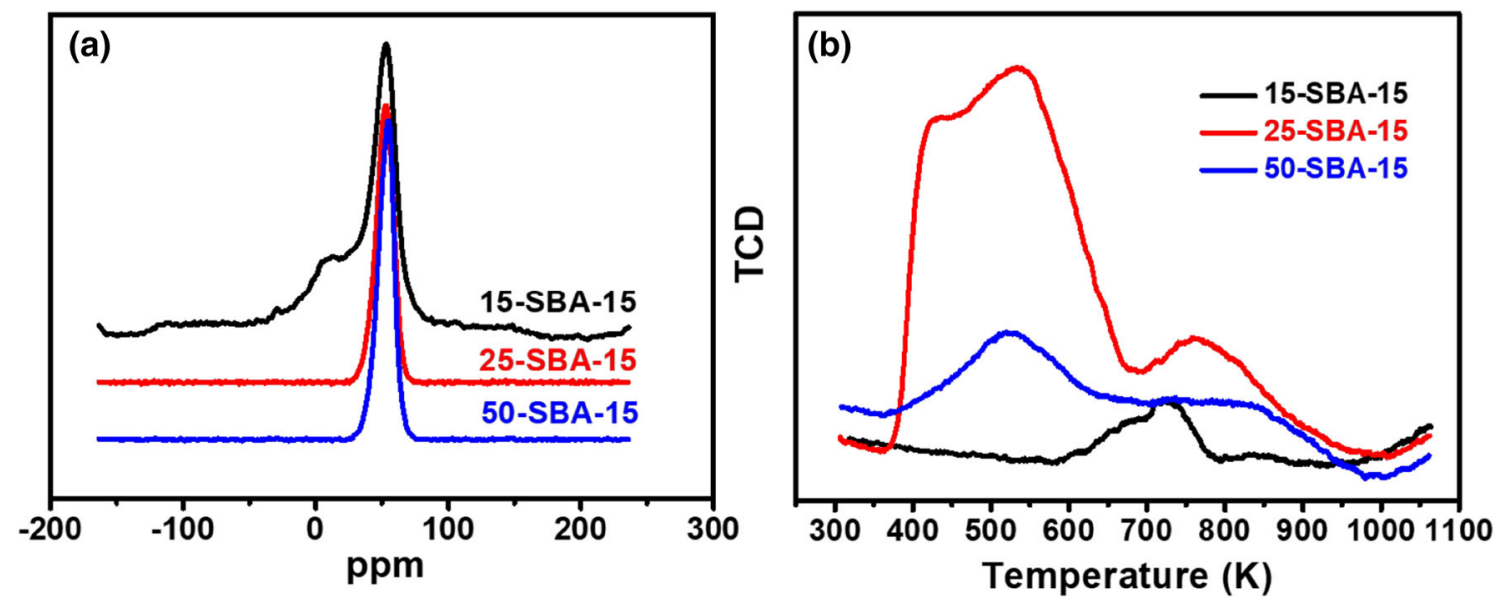

Figure 5. (a) ${ }^{27} \mathrm{Al}$ MAS NMR spectra and (b) $\mathrm{NH}_{3}$-TPD spectra of samples: 15-SBA-15 (black line), 25-SBA-15 (red line) and 50-SBA-15 (blue line).

exhibits that some $\mathrm{Al}$ was lost during the preparation progress.

\section{5 ${ }^{27} \mathrm{Al}$ MAS NMR and $\mathrm{NH}_{3}-\mathrm{TPD}$ results analysis}

Figure 5a is the ${ }^{27} \mathrm{Al}$ NMS spectra of materials. The signal of 15-SBA-15 can be observed at two points of $\delta=55 \mathrm{ppm}$ and $\delta=0 \mathrm{ppm}$. The signal of $\delta=55 \mathrm{ppm}$ is related to the skeleton tetra-coordinated aluminum, and the aluminum entering the material skeleton can produce strong acid centers. ${ }^{34}$ The signal of $\delta=0 \mathrm{ppm}$ derives from the non-skeleton six coordination aluminum, while the non-skeleton aluminum possesses lower acid. 25-worm-like and 50-worm-like samples only produce a signal at the position of $\delta=55 \mathrm{ppm}$ in the spectra, indicating that $\mathrm{Al}$ exists in the material skeleton in a tetra-coordinated state with a stronger acid. Moreover, the peak intensity of 50-worm-like sample is higher than that of 25 -SBA-15, indicating that the high content of aluminum has been entered into the skeleton, which is consistent with the above XRD analysis.

Figure $5 \mathrm{~b}$ shows the $\mathrm{NH}_{3}$-TPD spectra of samples with a different molar ratio of $\mathrm{Si} / \mathrm{Al}$. The results demonstrate that 15-SBA-15 exhibits a wide $\mathrm{NH}_{3}$ desorption peak at about $725 \mathrm{~K}$, indicating that aluminum has been entered the mesoporous framework and produced a certain acid center. There were two $\mathrm{NH}_{3}$ desorption peaks in 50-SBA-15 at $525 \mathrm{~K}$ and $820 \mathrm{~K}$, belonging to weak and strong acid, respectively. The high crystallinity of 50-SBA-15 belongs to the acidic character of ZSM5. The $\mathrm{NH}_{3}$ desorption peak of 25-SBA-15 indicates strong acid. Besides, the high-temperature desorption peak $(770 \mathrm{~K})$ is slightly lower than that of 50-SBA- 15 .

\subsection{Analysis of tert-butylated phenol reaction}

Mesoporous molecular sieve SBA-15 and pore wall crystallized SBA-15 were investigated for the reaction of phenol and tert-butanol. It can be seen from the results of the tert-butylation of phenol in Table 1. The catalyst SBA-15 has very low activity with phenol conversion of only $2.2 \%$. The phenol can be converted over catalysts of n-SBA-15 to 2-tert-butylphenol (2-TBP), 4tert-butylphenol (4-TBP), 2,4-di-tert-butylphenol (2,4di-TBP) and others. It is indicated that the introduction of $\mathrm{Al}$ element within the microporous zeolite structure enhances the acidity of the material and increases the conversion of phenol. In addition, the co-existence of the parent SBA-15 mesoporous structure in the catalysts not only provides the large specific surface area and a spacious channel but also gives a good environment for the generation and transmission of macromolecule products. The sample of 25-SBA-15 with higher content of aluminum possesses higher catalytic performance, in which the conversion of phenol is over $96 \%$, and the selectivity of 2,4-di-TBP is larger than $50 \%$. The high catalytic activity is mainly attributed to the fact that the two-dimensional hexagonal mesoporous structure of the parent SBA-15 maintains well and the parent SBA-15 pore wall partially crystallizes into ZSM-5 crystals and/or structural units. However, as to 50-SBA15 , the two-dimensional hexagonal pore of SBA-15 disappears due to the high crystallization of 50-SBA15 , which is a disadvantage of the product diffusion. The catalytic performance over 50-SBA-15 cuts down in terms of phenol conversion $(61.7 \%)$ and the selectivity of 2,4-di-tert-butylphenol (48.6\%). For 15-SBA-15, the two-dimensional hexagonal pores maintain well, but 15-SBA-15 with no crystallization hampers the 
Table 1. Results of alkylation of phenol tert-butanol.

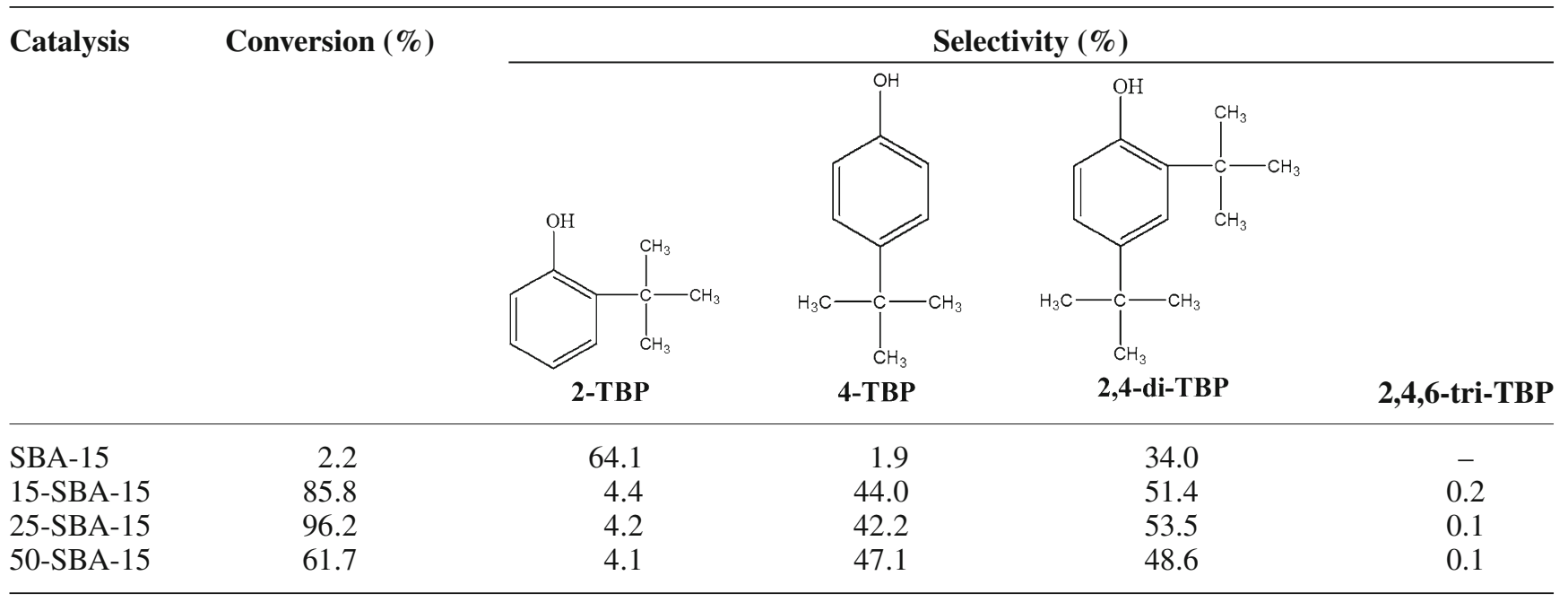

Reaction temperature $=418 \mathrm{~K}$; Phenol: TBA $=1: 2.5$ (molar ratio); WHSV $=2.20 \mathrm{~h}^{-1}$; TBP corresponding to tert-butyl phenol. The products were withdrawn and quantified after the reaction for $2 \mathrm{~h}$.

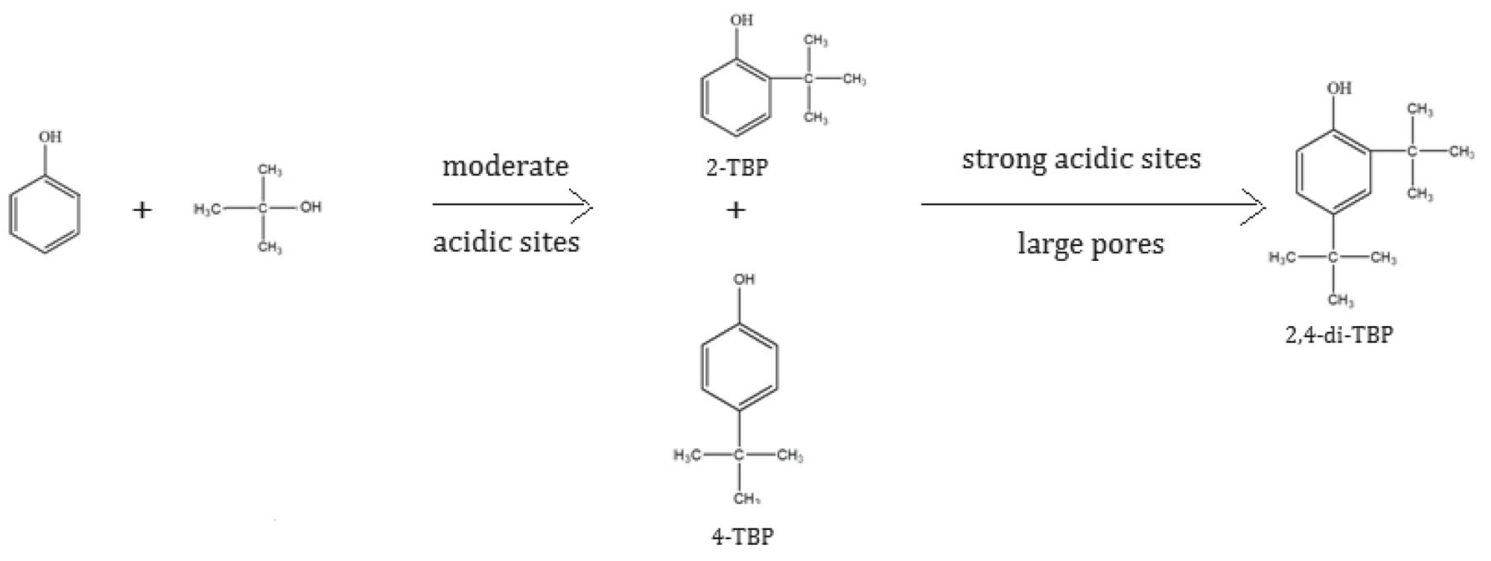

Figure 6. The probable mechanism of tert-butylation of phenol.

reaction of phenol and tert-butanol due to the weak acid sites.

As can be seen from Table 1, increasing aluminum content in the catalyst increases the conversion initially. This phenomenon can be explained as follows: the acidity of the catalyst with low aluminum percentage is weak, which leads to a relatively low catalytic activity and selectivity of 2,4-di-TBP. Compared with the catalyst 50-SBA-15 with low aluminum percentage, more $\mathrm{Al}$ atoms are incorporated into the silica framework of the 25-SBA-15 and a stronger acidity is formed. Thus, the catalytic performance over the catalyst 25-SBA-15 is obviously higher than those over the catalyst 50-SBA15 . In addition, a further increase in aluminum content in the catalyst 15-SBA-15 decreases the conversion. This phenomenon can be ascribed to the fact that more $\mathrm{Al}$ atoms are not incorporated into the silica framework of the 15-SBA-15. These results can be confirmed by ${ }^{27} \mathrm{Al}-$ MAS NMR and $\mathrm{NH}_{3}$-TPD results.
The probable mechanism of the catalytic transformations is shown in Figure 6. It was reported that the alkylation of phenol by tert-butanol is an acid-catalyzed reaction. In principle, the strong acidity of microporous molecular sieves is beneficial to this reaction. Therefore, the crystalline skeleton of microporous molecular sieves can provide acidic sites of tert-butylation of phenol. However, the small pore size of micropores molecular sieves $(<2 \mathrm{~nm})$ makes it very difficult for the large size molecular to diffuse effectively in the pore system. Accordingly, the reaction activity of tert-butylation of phenol over the microporous molecular sieves is low. In addition, mesoporous molecular sieve, such as Al-MCM-41, has large pore channels. However, its catalytic activity is still low, which should be ascribed to weak acidity of amorphous mesoporous walls. Hence, the coexistences of mesopore in the microporous molecular sieves enable easier diffusion of reactants and 


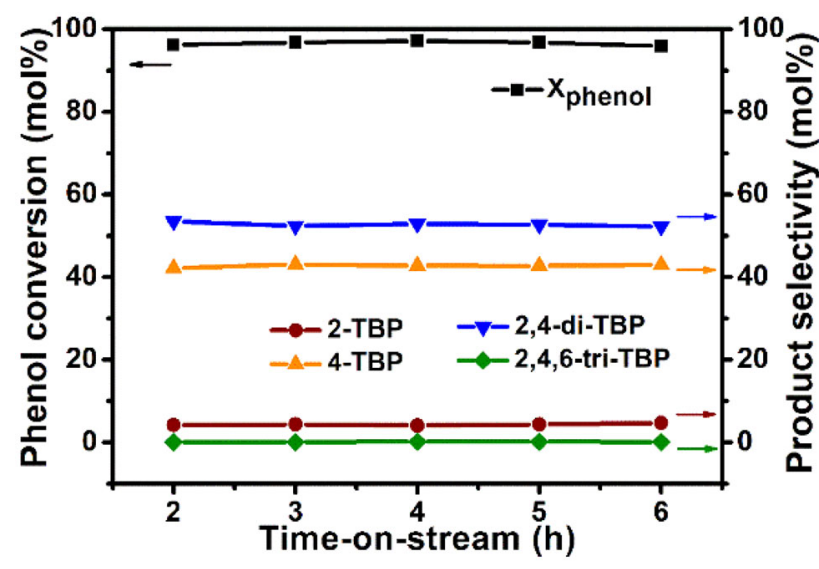

Figure 7. Effect of time-on-stream on phenol conversion and selectivity of products over 25-SBA-15 (Reaction condition: WHSV $=2.2 \mathrm{~h}^{-1}$, reaction temperature $=418 \mathrm{~K}, \mathrm{~N}_{2}$ flow velocity $=20 \mathrm{~mL} \mathrm{~min}^{-1}, \mathrm{n}_{\text {tert-butanol }} / \mathrm{n}_{\text {phenol }}=2.5: 1$ ).

products, favoring a high phenol conversion and 2,4-di-TBP selectivity.

Based on the results in Table 1, the catalyst 25-SBA15 displays better catalytic performance than others. In addition, comparing with others reported work in Table S2, ${ }^{3,35-42}$ the obtained catalyst in our study exhibits competitive catalytic performance for the catalytic activity on the reaction for tert-butylation of phenol. Furthermore, the reaction parameters, including reaction time, temperature and the molar ratio of tert-butanol/phenol were evaluated over the catalyst 25 SBA-15. The catalytic activity over $25-$ SBA-15 as a function of time for the reaction results is shown in Figure 7 . The products were collected at a time interval of an hour. As shown in Figure 7, after $2 \mathrm{~h}$ on stream, both the catalytic activity and product selectivity reach an equilibrium level. The phenol conversion is over $96 \%$ without significant change for time-on-stream, indicating that the catalyst $25-\mathrm{SBA}-15$ is stable at relatively high phenol conversion. The behavior of catalyst 25SBA-15 is assigned to its large pore size (as shown in $\mathrm{N}_{2}$ adsorption-desorption results) and/or relatively strong acidity (as shown in $\mathrm{NH}_{3}$-TPD results). In addition, the product selectivity to 2-TBP, 4-TBP and 2,4-di-TBP maintains stability within $6 \mathrm{~h}$, which exhibits that there is no secondary reaction, like dealkylation or transalkylation, over the catalyst 25-SBA-15.

Similar results were obtained for the alkylations of benzene with isopropanol using hierarchical zeolites. Higher activity and selectivity for the main product were achieved. ${ }^{40}$ As reported earlier, a crucial issue is that the microporous structure is a blockage of the pore mouths as a result of coke deposition, resulting in catalyst deactivation. The coke poisons the activity sites and

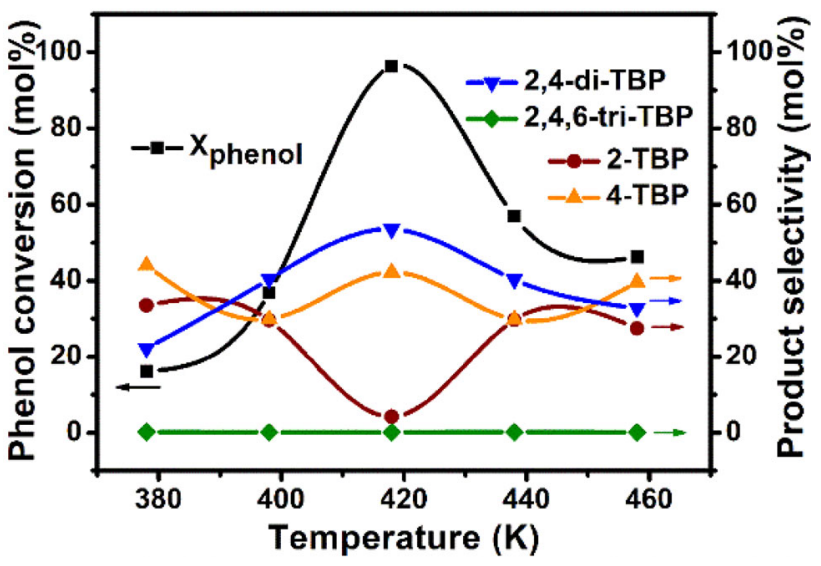

Figure 8. Effect of reaction temperature on phenol conversion and selectivity of products over 25-SBA-15 (Reaction condition: WHSV $=2.2 \mathrm{~h}^{-1}, \mathrm{~N}_{2}$ flow velocity = $20 \mathrm{~mL} \min ^{-1}, \mathrm{n}_{\text {tert}- \text { butanol }} / \mathrm{n}_{\text {phenol }}=2.5: 1$ ).

cannot be recovered. Many studies have shown that coke formation can be avoided using the large pore systems in mesoporous zeolite. ${ }^{41-44}$

Moreover, Figure 8 shows the effect of reaction temperature on the phenol conversion and product selectivity over 25-SBA-15 at a WHSV of $2.2 \mathrm{~h}^{-1}$, $\mathrm{N}_{2}$ flow velocity $=20 \mathrm{~mL} \mathrm{~min}^{-1}$ and $\mathrm{n}_{\text {tert-butanol }} / \mathrm{n}_{\text {phenol }}$ ratio of $2.5: 1$. The reaction temperature is one of the most important parameters on the conversion of phenol. ${ }^{45-47}$ The conversion of phenol first increases and then decreases with increasing reaction temperature. At a low reaction temperature of $378 \mathrm{~K}$, it exhibits poor catalytic performance with a low conversion of phenol $(16.1 \%)$. It can be explained that the low temperature is harmful to reactants activation as a consequence of the slow diffusion within the pores/channels of the catalyst. Additionally, the conversion of phenol increases from $36.8 \%$ to $96.2 \%$ with increasing reaction temperature from 398 to $418 \mathrm{~K}$. This result clearly indicates that the high temperature favors the reactants activation and diffusion. However, the conversion of phenol decreases to $46.2 \%$ at a temperature of $458 \mathrm{~K}$. The low conversion may be ascribed to both the predominant dealkylation and the diminishing availability of tertbutanol due to side reactions, like oligomerization or aromatization. $^{48}$

Similarly, the reaction temperature is an important influenced factor on the selectivity of products. With increasing reaction temperature, the selectivity to 2-TBP is higher at lower reaction temperature and decreases with the increasing reaction temperature. The selectivity to 4-TBP is similar to the wave line. The results in 4-TBP selectivity can be explained by the different diffusion kinetics of 4-TBP as compared to the 


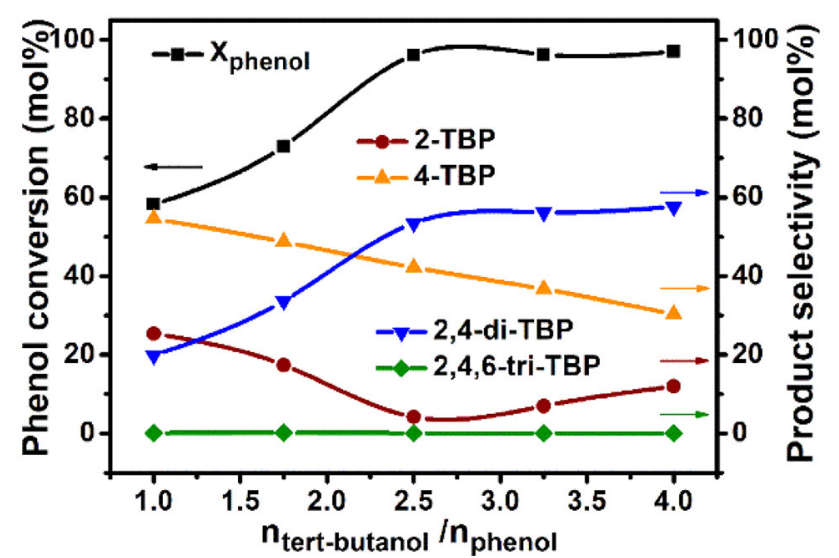

Figure 9. Effect of $n_{\text {tert-butanol }} / n_{\text {phenol }}$ on phenol conversion and selectivity of products over 25-SBA-15 (Reaction condition: WHSV $=2.2 \mathrm{~h}^{-1}$, reaction temperature $=$ $418 \mathrm{~K}, \mathrm{~N}_{2}$ flow velocity $=20 \mathrm{~mL} \mathrm{~min}^{-1}$, time-on-stream $=$ $2 \mathrm{~h})$.

other products. ${ }^{49}$ This is probably attributed to the high stability of tert-butyl cation at a low reaction temperature. Furthermore, the selectivity to 2,4-diTBP increases and reaches a maximum of $53.5 \%$ at a reaction temperature of $418 \mathrm{~K}$. Accordingly, a moderate reaction temperature $(418 \mathrm{~K})$ is helpful for the enhancement of the product selectivity to bulky 2, 4-diTBP.

Figure 9 shows the impact of $n_{\text {tert-butylalchol }} / n_{\text {phenol }}$ ratio on the catalytic results of 25-SBA-15 for the reaction at $418 \mathrm{~K}$ with $\mathrm{N}_{2}$ flow velocity of $20 \mathrm{~mL} \mathrm{~min}^{-1}$ and a space velocity of $2.2 \mathrm{~h}^{-1}$ for time-on-stream of $2 \mathrm{~h}$. It shows that the phenol conversion increases with increasing molar ratio of tert-butyl alcohol to phenol. The reaction reaches the equilibrium and the conversion of phenol reaches the maximum with the $n_{\text {tert-butylalchol }} / n_{\text {phenol }}$ of 2.5. It is well-known that the presence of competition between the polar molecule tert-butanol and phenol for adsorption sites. More tert-butanol molecules adsorb on the acid sites with increasing ratio of $n_{\text {tert-butylalchol }} / n_{\text {phenol }}$. The content of reaction intermediate iso-butene formed by dehydration of tert-butan finally promotes the alkylation reaction. Therefore, the conversion of phenol increases with increasing the molar ratio of tert-butanol in the reactants. The results obtained in this study are in good agreement with the reported literature. ${ }^{50}$ Furthermore, the selectivity of 2-TBP and 4-TBP decreases and the selectivity of 2,4-di-TBP increases with an increase in a molar ratio of tert-butyl alcohol to phenol. It may be the reason that the increase of the tertbutanol content can further improve the alkylation of monoalkylated products, such as 2-TBP and 4-TBP to 2,4-di-TBP.

\section{Conclusions}

Using the mesoporous molecular sieve SBA-15 as a precursor, a microporous-mesoporous molecular sieve ZSM-5/SBA-15 with different wall crystallinity can be obtained by hydrothermal crystallization. The increase in initial aluminum content results in low crystallinity of pores. Moreover, the mesoporous structure remains well, favoring high catalytic activity in the reaction of phenol tert-butanol. When lowering the initial content of aluminum, the crystallinity of the pore wall becomes high, and the two-dimensional hexagonal structure of the parent SBA-15 is destroyed. Such activity of phenol tert-butanol is reduced due to the absence of a largesized mesoporous channel.

\section{Supplementary Information (SI)}

Figures S1-S2 and Tables S1-S2 are available at www.ias.ac. in/chemsci.

\section{Acknowledgements}

Financial support from the National Natural Science Foundation of China (Grant Nos. 21561024, 21661026 and 21606219 ) is gratefully acknowledged.

\section{References}

1. Knop A and Pilato L A 1985 Phenolic Resin Chemistry (Berlin: Springer)

2. Dumitriu E and Hulea V 2003 Effects of channel structures and acid properties of large-pore zeolites in the liquid-phase tert-butylation of phenol J. Catal. 218249

3. Anand R, Maheswari R, Gore K U and Tope B B 2003 Tertiary butylation of phenol over HY and dealuminated HY zeolites J. Mol. Catal. A Chem. 193251

4. Chumbhale V R K, Gore U S, Hegde G, Kim J S, Lee S B and Choi M J 2003 Tertiary butylation of phenol over HY and dealuminated HY zeolites J. Ind. Eng. Chem. 9 748

5. Padmasri A H, Kumari V D and Rao P K 1998 tertButylation of phenol with isobutanol over magnesiumaluminum hydrotalcites Stud. Surf. Sci. Catal. 113563

6. Yadav G D and Doshi N S 2002 Alkylation of phenol with methyl-tertbutyl ether and tert-butanol over solid acids: efficacies of clay-based catalysts Appl. Catal. A Gen. 236129

7. Shinde A B, Shrigadi N B and Samant S D 2004 tertButylation of phenols using tert-butanol in the presence of $\mathrm{FeCl}_{3}$-modified montmorillonite K10 Appl. Catal. A Gen. 2765

8. Devassy B M, Shanbhag G V, Mirajkar S P, Böhringer W, Fletcher J and Halligudi S B 2005 Silicotungstatemodified zirconia as an efficient catalyst for phenol tertbutylation J. Mol. Catal. A Chem. 233141

9. Usha Nandhini K, Arabindoo B, Palanichamy M and Murugesan V 2004 t-Butylation of phenol over mesoporous aluminophosphate and heteropolyacid supported 
aluminophosphate molecular sieves J. Mol. Catal. A Chem. 223201

10. Vinu A, Usha Nandhini K, Murugesan V, Böhlmann W, Umanaheswari V, Pöppl A and Hartmann M 2004 Mesoporous FeAlMCM-41: An improved catalyst for the vapor phase tert-butylation of phenol Appl. Catal. A Gen. 2651

11. Yadav G D and Pathre G S 2005 Novel mesoporous solid superacids for selective C-alkylation of m-cresol with tert-butanol Micropor. Mesopor. Mater. 8916

12. Yadav G D and Pathre G S 2006 Novelties of a superacidic mesoporous catalyst UDCaT-5 in alkylation of phenol with tert-amyl alcohol Appl. Catal. A Gen. 297 237

13. Mathew T, Rao B S and Gopinath C S 2004 Tertiary butylation of phenol on $\mathrm{Cu} 1-\mathrm{xCoxFe}_{2} \mathrm{O}_{4}$ : Catalysis and structure-activity correlation J. Catal. 222107

14. Baute D, Zimmermann H, Kababya S, Vega S and Goldfarb D 2005 Synthesis of MCM-41 with a phosphonium template Chem. Mater. 173723

15. Chiang W S, Fratini E, Baglioni P, Georgi D, Chen J $\mathrm{H}$ and Liu Y 2016 Methane adsorption in model mesoporous material, SBA-15, studied by small-angle neutron scattering J. Phys. Chem. C $\mathbf{1 2 0} 4354$

16. Sayari A and Yang Y 2005 SBA-15 templated mesoporous carbon: new insights into the SBA-15 pore structure Chem. Mater. 176108

17. Hoang V T, Huang Q, Eić M, Do T O and Kaliaguine S 2005 Structure and diffusion characterization of SBA-15 materials Langmuir 212051

18. Linton P and Alfredsson V 2008 Growth and morphology of mesoporous SBA-15 particles Chem. Mater. 20 2878

19. Yang X Y, Chen L H, Li Y, Rooke J C, Sanchez C and Su B L 2017 Hierarchically porous materials: synthesis strategies and structure design Chem. Soc. Rev. 46 481

20. Petkov N, Hölzl M, Metzger T H, Mintova S and Bein T 2005 Ordered Micro/mesoporous composite prepared as thin films J. Phys. Chem. B 1094485

21. White R J, Fischer A, Goebel C and Thomas A 2014 A Sustainable template for mesoporous zeolite synthesis $J$. Am. Chem. Soc. 1362715

22. Jacobsen C J H, Madsen C, Houzvicka J, Schmidt I and Carlsson A 2000 Mesoporous zeolite single crystals $J$. Am. Chem. Soc. 1227116

23. Xu J, Zhang Q, Guo F, Wang Y and Xie J 2018 Highly hydrothermal stable mesoporous molecular sieves (TZM) prepared by the self assembly of zeolitic subunits from ZSM-5 desilication and their catalytic performance for $\mathrm{CO}_{2}$ reforming of $\mathrm{CH}_{4}$ New J. Chem. 42 19000

24. Xu H, Zhang D and Wu F 2018 Effect of the template on the hydrothermal synthesis of mixed molecular sieves for methanol dehydration Environ. Progr. Sustain. Energ. 37 2132

25. Zhang P, Liu H, Yue Y, Zhu H and Bao X 2018 Direct synthesis of hierarchical SAPO-11 molecular sieve with enhanced hydroisomerization performance Fuel Proces. Technol. 17972

26. Li Z, Zhong Z, Zhang B, Gu J and Shi K 2018 Catalytic Fast Pyrolysis of Bamboo over Micro-mesoporous
Composite Molecular Sieves Using Py - GC/MS Energ. Technol. 6728

27. Tao H, Nguyen N T, Hei X H, Nguyen C N, Tsai H H, Chang I C and Chang C T 2016 Synthesis, Characterization and Application of N-Ti/13X/MCM-41 Mesoporous Molecular Sieves J. Nanosci. Nanotechnol. 166567

28. Huang L M, Guo W P, Deng P, Xue Z Y and Li Q Z 2000 Investigation of synthesis MCM-41/ZSM-5 composites J. Phys. Chem. B 1042817

29. Kloetstra K R, van Bekkum H and Jansen J C 1997 Mesoporous material containing framework tectosilicate by pore-wall recrystallization Chem. Commun. 2281

30. Verhoef M J, Kooyman P J, Van Der Waal J C and van Bekkum H 2001 Partial transformation of nanosized MFI type crystallites Chem. Mater. 13683

31. Yue M B, Sun L B, Zhuang T T, Dong X, Chun Y and Zhu J H 2008 Directly transforming as-synthesized MCM-41 to mesoporous MFI zeolite J. Mater. Chem. 182044

32. Lysenko N D, Il'in V G and Yaremov P S 2011 Structural and sorption characteristics of the products from zeolitization of SBA-15 in the presence of tetraalkylammonium hydroxides Theor. Exp. Chem. 47257

33. Zhang Y W, Okubo T and Ogura M 2005 Synthesis of mesoporous aluminosilicate with zeolitic characteristics using vapor phase transport Chem. Commun. 2719

34. Fyfe C A, Bretherton J L and Lam L Y 2001 Solid-State NMR detection, characterization, and quantification of the multiple aluminum environments in US-Y catalysts by Al MAS and MQMAS experiments at very high field J. Am. Chem. Soc. 1235285

35. Yin C Y, Feng L L, Ni R, Hu L Y, Zhao X and Tian D 2014 One-pot synthesis of hierarchically nanoporous ZSM-5 for catalytic cracking Powder Technol. 25310

36. García-Martínez J, Johnson M, Valla J, Li K H and Ying J Y 2012 Mesostructured zeolite Y-high hydrothermal stability and superior FCC catalytic performance Catal. Sci. Technol. 2987

37. Na J P, Liu G Z, Zhou T Y, Ding G C, Hu S L and Wang L 2013 Synthesis and catalytic performance of ZSM-5/MCM-41 zeolites with varying mesopore size by surfactant-directed recrystallization Catal. Lett. 143 267

38. Srivastava R, Choi M and Ryoo R 2006 Mesoporous materials with zeolite framework: Remarkable effect of the hierarchical structure for retardation of catalyst deactivation Chem. Commun. 4489

39. Jin J S, Peng C Y, Wang J J, Liu H T, Gao X H, Liu H H and Xu C Y 2014 Facile Synthesis of mesoporous zeolite $\mathrm{Y}$ with improved catalytic performance for heavy oil fluid catalytic cracking Ind. Eng. Chem. Res. 533406

40. Sakthivel A, Badamali S K and Selvam P 2001 Vapour phase tertiary butylation of phenol over sulfated zirconia catalyst Catal. Lett. 72225

41. Badamali S K, Sakthivel A and Selvam P 2000 Tertiary butylation of phenol over mesoporous H-FeMCM-41 Catal. Lett. 65153

42. Sakthivel A, Badamali S K and Selvam P 2000 paraSelective t-butylation of phenol over mesoporous. HAlMCM-41 Micropor. Mesopor. Mater. 39457

43. Karthik M, Tripathi A K, Gupta N M, Vinu A, Hartmann M, Palanichamy M and Murugesan V 2004 Characterization of Co, Al-MCM-41 and its activity 
inthe t-butylation of phenol using isobutanol Appl. Catal. A Gen. 268139

44. Ojha K, Pradhan N C and Samanta A N 2006 Alkylation of phenol with tert-butyl alcohol over a catalyst synthesized from coal fly ash J. Chem. Technol. Biotechnol. 81 659

45. Zhang K, Huang C H, Zhang H B, Xiang S H, Liu S Y, Xu D and Li H X 1998 Alkylation of phenol with tert-butyl alcohol catalysed by zeolite $\mathrm{H} \beta$ Appl. Catal. A Gen. 166 89

46. Zhang $\mathrm{K}$, Zhang $\mathrm{H} \mathrm{B}, \mathrm{Xu} \mathrm{G} \mathrm{H}$, Xiang $\mathrm{S} \mathrm{H}$, Xu D, Liu S Y and Li H X 2001 Alkylation of phenol with tert-butyl alcohol catalyzed by large pore zeolites Appl. Catal. A Gen. 207 183
47. Huang J H, Xing L H, Wang H S, Li Gong, Wu S J, Wu T H and Kan Q B 2006 Tertiary butylation of phenol over hexagonal p6mm mesoporous aluminosilicates with enhanced acidity J. Mol. Catal. A Chem. 25984

48. Zhang K, Huang C, Zhang H, Xiang S, Liu S, Xu D and Li H 1998 Alkylation of phenol with tert-butyl alcohol catalysed by zeolite $\mathrm{H} \beta$ Appl. Catal. A 16689

49. Deka R C and Vetrivel R 1998 Adsorption sites and diffusion mechanism of alkylbenzenes in large pore zeolite catalysts as predicted by molecular modeling techniques J. Catal. 17488

50. Subramanian S, Mitra A, Satyanarayana C V V and Chakrabarty D K 1997 Para-selective butylation of phenol over silicoaluminophosphate molecular sieve SAPO11 catalyst Appl. Catal. A 159229 